\title{
Molecular Evidence of the Relationship Between a Virus Associated with Flat Apple Disease and Cherry rasp leaf virus as Determined by RT-PCR
}

\author{
D. James, Centre for Plant Health, Canadian Food Inspection Agency, 8801 East Saanich Road, Sidney, B.C., \\ Canada, V8L 1H3; and W. E. Howell and G. I. Mink, Washington State University, NRSP5/IR2, 24106 Bunn Rd., \\ Prosser 99350
}

\begin{abstract}
James, D., Howell, W. E., and Mink, G. I. 2001. Molecular evidence of the relationship between a virus associated with flat apple disease and Cherry rasp leaf virus as determined by RT-PCR. Plant Dis. 85:47-52.

Flat apple disease-associated virus (FAV) was mechanically transmitted to the propagation host Chenopodium quinoa and double-stranded (ds)RNA recovered using CFII chromatography. Purified dsRNA was used to generate cDNA clones which were sequenced and the information used to design oligonucleotide primers for reverse transcription-polymerase chain reaction (RTPCR) and tube capture (TC)/RT-PCR analyses. Oligonucleotide primers for RT-PCR analysis and dot blot hybridization using digoxigenin-labeled cDNA clones were used for the detection of FAV and Cherry rasp leaf virus (CRLV) in C. quinoa, in leaf and bud wood tissue of apple, or both. Primers JQ3D33FF/FR amplified a virus-specific 429-bp fragment and reliably detected all isolates of FAV and CRLV tested by RT-PCR and TC/RT-PCR. Primers JQ2C1FF/FR amplified a 370-bp fragment and detected FAV and some isolates of CRLV. Comparison of amino acid residues derived from the 429-bp fragments of FAV and CRLV gave 95\% identity. The RTPCR assays provided strong evidence of a relationship between FAV and CRLV. These assays were also used to confirm virus elimination in apple plants after heat therapy. Western blot analysis of FAV revealed capsid protein subunits of approximately 22 and $24 \mathrm{kDa}$. Our data support biological and serological evidence that FAV and CRLV are isolates of the same virus. Searches of the database produced sequence matches only with RNA2 of Apple latent spherical virus (ALSV), a new member of the family Comoviridae. This suggests that both primer pairs presumably target regions on RNA2 of FAV/CRLV and that these viruses may be more closely related to ALSV than to other members of this family.
\end{abstract}

Flat apple disease is one of a number of fruit-deforming diseases affecting apple (Malus domestica Borkh.) (5). The taste and appearance of the fruit are affected, reducing their value or even making them unmarketable (15). Symptoms of flat apple as described on cvs. Red Delicious and Golden Delicious include small flattened fruit, reduced lateral branch growth, and upward rolling leaves (5). The causal agent or agents of flat apple disease and rasp leaf disease in cherry (Prunus avium L.) have been shown to be related by using inocula of flat apple to induce symptoms of rasp leaf in sweet cherry and vice versa $(17,18)$. The Cherry rasp leaf virus (CRLV) has been identified as an isometric virus $30 \mathrm{~nm}$ in diameter, with two single-stranded RNA

Corresponding author: D. James

E-mail: jamesd@em.agr.ca

This project was supported in part by a grant from the Washington Tree Fruit Research Commission.

Accepted for publication 13 September 2000.

Publication no. D-2000-1030-03R

This article is in the public domain and not copyrightable. It may be freely reprinted with customary crediting of the source. The American Phytopathological Society, 2001. species of sizes $2.0 \times 10^{6}$ and $1.5 \times 10^{6}$ and capsid proteins of 22.5 and $24 \mathrm{kDa}(19,20)$. CRLV and Flat apple disease-associated virus (FAV) are serologically related and have similar herbaceous host range and symptomatology $(17,19)$. The nematode Xiphinema americanum is a vector of CRLV $(4,16)$.

Control and detection of the agent associated with flat apple disease are difficult and challenging. $M$. domestica cv. Red Delicious is a woody indicator for flat apple disease (15), but caution is required in diagnosing this disease strictly on the basis of fruit symptoms because chemical sprays may cause flat apples (5). Nucleic acidbased diagnostic techniques such as reverse transcription-polymerase chain reaction (RTPCR) are highly sensitive and reliable for virus detection in apple (7). The objectives of this research were to obtain nucleotide sequence information that would facilitate the development of RT-PCR diagnostic tools for FAV and allow comparisons at the molecular level with CRLV.

\section{MATERIALS AND METHODS}

Virus sources. The FAV isolate JCQ121-3 was isolated from a symptomatic Red Delicious apple tree from Prosser, WA. FAV JCQ121-4 is the same isolate graft-inoculated to a different Red
Delicious apple tree. CRLV isolates in cherry were 1148-04 and 1160-01 from Sidney, B.C.; 95CI193 and WSU-1 from Prosser, WA.; KG-1 and SO-1-2 from the Okanagan, B.C.; SC-DP and SC-RC in cherry and CRLV isolates CP-1, CP-A, and $\mathrm{CP}-\mathrm{S}$ in peach from Colorado State University. Tissue extracts were prepared from leaf or dormant budwood material which consisted of fresh, frozen at $-80^{\circ} \mathrm{C}$, or freeze-dried tissues.

Mechanical transmission. Chenopodium quinoa (Willd.) is a diagnostic and propagation species for CRLV (19) and was used in mechanical transmission studies with FAV. Young leaves of flat appleaffected Red Delicious apple (JCQ121-3) were triturated in $0.03 \mathrm{M}$ potassium phosphate buffer, $\mathrm{pH}$ 7.0, containing $0.02 \mathrm{M}$ mercaptoethanol and $1 \%$ polyvinylpyrrolidone (molecular mass $=10,000$; PPMP buffer) and rub inoculated on leaves of $C$. quinoa seedlings.

Western blot analysis. Leaf tissues from healthy and infected $C$. quinoa plants were triturated in $0.01 \mathrm{M}$ potassium phosphate buffer ( $\mathrm{pH} 7.0$ ) containing $0.02 \mathrm{M}$ diethyldidithiocarbamic acid, sodium salt, $0.04 \mathrm{M}$ sodium thioglycolate, and $0.5 \%$ nicotine. Proteins were resolved under denaturing conditions by sodium dodecyl sulfate-polyacrylamide gel electrophoresis as described by Laemmli (10), and electroblotted, using a semi-dry transfer unit (Bio-Rad, Mississauga, Ontario), onto nitrocellulose membranes $(0.45-\mu \mathrm{m}$ pore size; Schleicher \& Schuell, Keene, NH). Prestained markers (Bio-Rad) were used to assess transfer of the proteins from the gel to the membrane. Blots were screened with a polyclonal antibody against CRLV as the primary antibody, and goat anti-rabbit alkaline phosphatase conjugate (Bio-Rad) as the secondary antibody. Nitro blue tetrazolium chloride and 5-bromo-4-chloro-3indolyl phosphate toluidine salt (NBTBCIP) substrates were used as recommended by the supplier (Bio-Rad). The blocking buffer consisted of Tris-buffered saline (TBS; $0.05 \mathrm{M}$ Tris, $0.15 \mathrm{M}$ sodium chloride, $\mathrm{pH} 7.4$ ) containing $2 \%$ skimmed milk powder to minimize spurious cross reactions (23).

Double-stranded RNA extraction. Double-stranded (ds)RNA was extracted from FAV-infected $C$. quinoa using a procedure similar to that described by Morris and Dodds (14). 
Table 1. Nucleotide sequences of oligonucleotide primers used in reverse transcription-polymerase chain reaction assays of the Flat apple disease-associated virus

\begin{tabular}{lll}
\hline Oligonucleotide $^{\mathbf{a}}$ & \multicolumn{1}{c}{ Sequence } & $\mathbf{T}_{\mathbf{m}}^{\mathbf{b}}$ \\
\hline JQ2C1FF & 5'-TGC CCG ACC AAA TGC CAG-3' & 58 \\
JQ2C1FR & 5'-AGG AGA AGT ATT AAC AAC TG-3' & 64 \\
JQ2C1RR & 5'-GAG ATT CAG AGC CCT CAA AGC-3' & 64 \\
JQ2D1FF & 5'-CAG TTG GTG ACA CTG GAA TAG C-3' & 66 \\
JQ2D1RR & 5'-TGA GAG ATT CAG AGC CCT C-3' & 58 \\
JQ3D3FF & 5'-GCC AGT TTC TCC AGT GAA CC-3' & 62 \\
JQ3D3FR & 5'-CAG TTG AAC GGA TTT AAC C-3' & 54 \\
\hline
\end{tabular}

${ }^{a}$ Oligonucleotides ending with the letter $\mathrm{F}$ were used as forward or sense primers; those ending with letter $\mathrm{R}$ as reverse or antisense primers.

b The formula $T_{m}=2(A+T)+4(G+C)$ was used to calculate the melting temperature of the primers (3).

Table 2. Isolates of Flat apple disease-associated virus (FAV) and Cherry rasp leaf virus (CRLV) detected by reverse transcription-polymerase chain reaction (RT-PCR) or tube capture (TC)/RT-PCR

\begin{tabular}{|c|c|c|c|c|}
\hline \multirow[b]{2}{*}{ Isolate } & \multirow[b]{2}{*}{ Identity } & \multirow[b]{2}{*}{ Origin } & \multicolumn{2}{|c|}{ PCR detection ${ }^{a}$} \\
\hline & & & 3D3FF \& FR & 2C1FF \& FR \\
\hline $121-3$ & FAV & Prosser, WA & ++ & ++ \\
\hline $121-4$ & FAV & Prosser, WA & ++ & ++ \\
\hline $1148-04$ & CRLV & Sidney, BC & ++ & $\mathrm{nr}$ \\
\hline $1160-01$ & CRLV & Sidney, BC & ++ & $\mathrm{nr}$ \\
\hline 95CI193 & CRLV & Prosser, WA & ++ & ++ \\
\hline WSU-1 & CRLV & Prosser, WA & ++ & ++ \\
\hline KG-1 & CRLV & Okanagan, BC & ++ & ND \\
\hline SO-1-2 & CRLV & Okanagan, BC & ++ & ND \\
\hline SC-DP & CRLV & Grand Junction, CO & ++ & $\mathrm{nr}$ \\
\hline SC-RC & CRLV & Grand Junction, CO & ++ & $\mathrm{nr}$ \\
\hline $\mathrm{CP}-1$ & CRLV & Grand Junction, CO & ++ & $\mathrm{nr}$ \\
\hline CP-A & CRLV & Grand Junction, CO & ++ & $\mathrm{nr}$ \\
\hline CP-S & CRLV & Grand Junction, CO & ++ & $\mathrm{nr}$ \\
\hline
\end{tabular}

${ }^{a}$ Detection by RT-PCR or TC/RT-PCR using the primer pairs JQ3D3FF and JQ3D3FR or JQ2C1FF and JQ2C1FR; ++ = positive, $\mathrm{nr}=$ no reaction, and $\mathrm{ND}=$ not done.

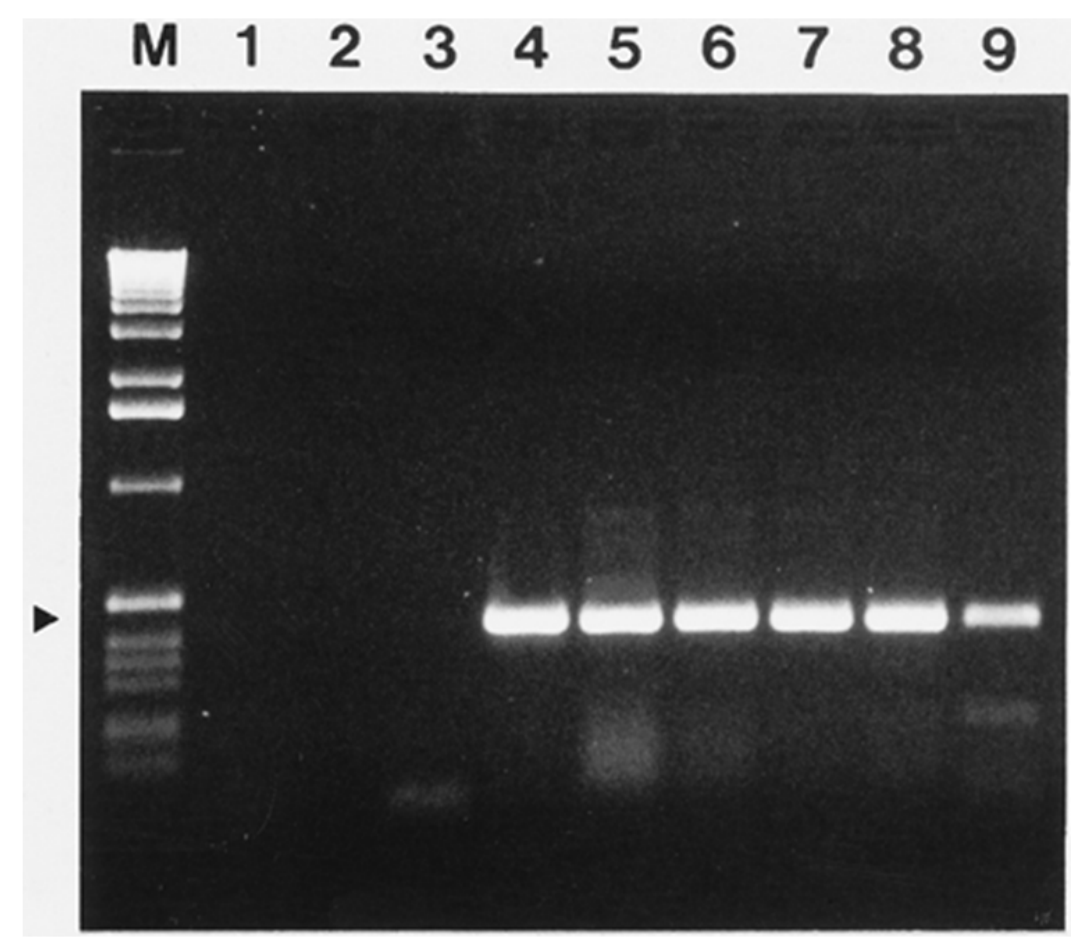

Fig. 1. Reverse transcription-polymerase chain reaction detection of isolates of Flat apple diseaseassociated-virus (FAV) and Cherry rasp leaf virus (CRLV) using primers JQ3D3FF and JQ3D3FR. Lane M, 1-kb DNA ladder; lanes 1 to 9, healthy Chenopodium quinoa, healthy apple, healthy cherry, C. quinoa with FAV (JCQ121-3), apple with FAV (JCQ121-3), apple with FAV (JCQ121-4), cherry with CRLV (WSU-1), cherry with CRLV (95CI193), and cherry with CRLV (1148-04), respectively. The arrow indicates the position of the 429-bp band.
Synthesis, cloning, and sequencing of cDNA. FAV-associated dsRNA was purified by electrophoresis using low melt preparative grade agarose (Bio-Rad). The dsRNA was recovered from the gel by phenol/chloroform extraction and ethanol/sodium acetate precipitation. The purified dsRNA was resuspended in diethylpyrocarbonate-treated double distilled water (depc $\mathrm{H}_{2} \mathrm{O}$ ) and used as a template for cDNA synthesis carried out as described by James and Upton (9). Taq DNA polymerase-amplified cDNA fragments were ligated into the $\mathrm{pCR}^{(\mathrm{R})} 2.1 \mathrm{TOPO}$ Vector and cloned using the TOPO TA Cloning Kit, as directed by the supplier (Invitrogen, Carlsbad, CA). Plasmids with cDNA inserts were sequenced using a Long Read IR 4200 automated sequencer (LI-COR Biotech, Lincoln, NE). Sequencing of the inserts in $\mathrm{pCR}^{(\mathrm{R})} 2.1$ vector was carried out using the M13 forward and M13 reverse primers in combination with the SequiTherm Excel II DNA LC sequencing kit (Epicentre Technologies, Madison, WI). The two primers were labeled with different fluorescent dyes, permitting the simultaneous sequencing of both DNA strands in a single direction. Nucleotide sequence data were compiled and analysed using the GCG program package version Unix-7.3 (2) and database searches were performed with BLAST programs at the National Centre for Biotechnology Information (NCBI, National Institutes of Health, Bethesda, MD).

Extraction of total RNA and dot blot hybridization. Total RNA for dot blot hybridization and RT-PCR analysis was extracted from healthy and infected leaf tissue (100 mg) using the QIAGEN RNeasy Total RNA kit (QIAGEN, Chatsworth, CA). The extraction procedure used was essentially as described by the supplier except for budwood (bark) tissue as described by James and Upton (9). Bark shavings were prepared as described by MacKenzie et al. (12). RNA was eluted with $30 \mu \mathrm{l}$ of depc $\mathrm{H}_{2} \mathrm{O}$. Blotting of RNAs on Bio-Rad's Zeta-Probe membranes was carried out as described by James et al. (8).

Selected $\mathrm{pCR}^{(\mathrm{R})} 2.1$ TOPO vectors with FAV-derived cDNA inserts were cloned in TOPO 10 One Shot Competent cells obtained from Invitrogen. The plasmids were purified using Bio-Rad's Plasmid Miniprep Kit (Quantum Prep). Inserts ranging in size from 700 to $1,600 \mathrm{bp}$ were excised using EcoRI restriction enzyme, agarose gel purified, and digoxigenin labeled using Boehringer Mannheim's Dig DNA Labeling and Detection Kit. The probes were then used to screen membranes spotted with total RNA preparations, as described by James et al. (8).

RT-PCR and tube capture/RT-PCR. Synthetic oligonucleotide primers were based on the FAV isolate JCQ121-3 sequence using plasmids with inserts specific for FAV in dot blot hybridization studies. 
The melting temperatures of the primers (Table 1) were determined using a formula described by Griffin (3). A number of primer combinations were assessed, including JQ2C1FF and JCQ2C1FR, JQ2C1FF and JQ2C1RR, JQ2D1FF and JQ2D1RR, and JQ3D3FF and JQ3D3FR (Table 1). RT-PCR was performed as described previously (7) but with the following modifications. All oligonucleotide primers were used at a concentration of 14 pmol. The reverse transcription reaction mix consisted of $4 \mu \mathrm{l}$ of $5 \times$ First Strand buffer (Gibco BRL, Life Technologies, Burlington, Ontario), $2 \mu$ l of 0.1 M DTT, 1 $\mu \mathrm{l}$ of $10 \mathrm{mM}$ dNTP Mix, $0.5 \mu \mathrm{l}$ of RNase inhibitor, $1 \mu$ of SUPERSCRIPT II (Gibco BRL), and adjusted up to a final volume of $13 \mu \mathrm{l}$ with depc $\mathrm{H}_{2} \mathrm{O}$. The PCR reaction mix consisted of $2 \mu \mathrm{l}$ of $10 \mathrm{mM}$ dNTP mix, $3 \mu \mathrm{l}$ of $50 \mathrm{mM} \mathrm{MgCl}, 1 \mu \mathrm{l}$ of upstream primer $(14 \mathrm{pmol}), 1 \mu \mathrm{l}$ of downstream primer (14 pmol), $1 \mu \mathrm{l}$ of Taq DNA polymerase (Gibco BRL), $1 \mu$ l of Taq Extender PCR Additive (Stratagene, La Jolla, CA), and $10 \mu \mathrm{l}$ of $10 \times \mathrm{Taq}$ Extender buffer, adjusted to a final volume of $80 \mu \mathrm{l}$ with depc $\mathrm{H}_{2} \mathrm{O}$.

Tube capture (TC)/RT-PCR was carried out using a procedure similar to that described by James (7) with similar sample grinding buffers evaluated for effectiveness and reliability.

Sequence analysis of amplified products. PCR fragments were excised from a $1 \%$ agarose gel and purified using BioRad's DNA Purification Kit (Catalog \#732-6010). The fragments were generated using Taq DNA polymerase so that cloning and sequencing were carried out as described above.

Virus elimination by heat therapy. Symptomatic FAV-infected (JCQ121-3) Red Delicious apple plants were subjected to heat therapy. The mother trees were grown at 37 to $38^{\circ} \mathrm{C}$ for 75 days prior to the excision of 5-mm shoot tips (13) and cleft grafted onto succulent side branches of 1-year-old apple seedlings and grown at $25^{\circ} \mathrm{C}$ in a humid chamber until adapted to ambient conditions. Later, the plants were maintained in an insect-proof screenhouse and leaf samples were collected for RTPCR and TC/RT-PCR assays. These trees were eventually transplanted to field plots for fruit production.

\section{RESULTS}

Western blot analysis. Two distinct bands were detected in association with FAV-infected $C$. quinoa and Red Delicious apple (isolate JCQ121-3) using a polyclonal antiserum against CRLV (data not shown). The bands were estimated to have molecular masses of 22 and $24 \mathrm{kDa}$. Similar bands were not detected in healthy plants.

Dot blot hybridization. The digoxigenin-labeled cDNA clone pJQ2C2 was specific and reliable for the detection of FAV in $C$. quinoa and in Red Delicious apple. No reaction was observed with healthy plants. Dot blot hybridization using pJQ2C2 was less sensitive than RT-PCR, using serial dilutions of total RNA in depc $\mathrm{H}_{2} \mathrm{O}$ extracted from infected $C$. quinoa. The threshold limits were $10^{-2}$ (dot blot) and $10^{-7}$ (RT-PCR).

Primer design and RT-PCR analysis. Twelve white colonies with cDNA inserts of 700 to $1,600 \mathrm{bp}$ were sequenced and several represented overlapping sequences. Sequence data derived from a number of the clones, some of which were FAV-specific in dot blot hybridization, were used to design oligonucleotide primers. Primers with similar melting temperatures were selected and evaluated in RT-PCR using the following combinations: JQ2C1FF and JQ2C1FR, JQ2C1FF and JQ2C1RR, JQ2D1FF and JQ2D1RR, and JQ3D3FF and JQ3D3FR (Table 1). FAV and CRLV were detected by RT-PCR in fresh, frozen $\left(-80^{\circ} \mathrm{C}\right)$, or freezedried herbaceous, leaf, and budwood (bark) tissue of apple and cherry.
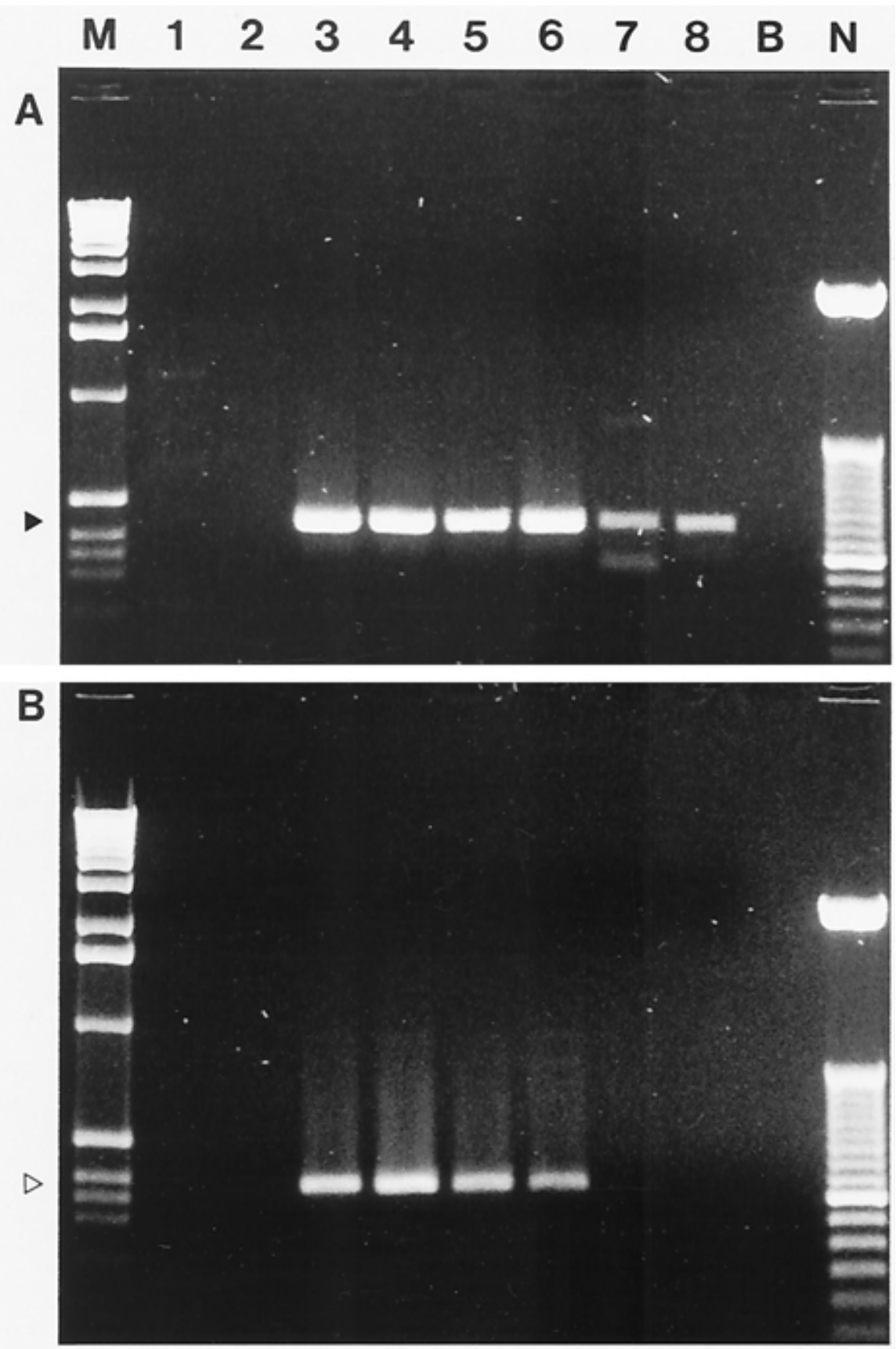

Fig. 2. Comparison of reverse transcription-polymerase chain reaction detection of Flat apple disease-associated-virus (FAV) and Cherry rasp leaf virus (CRLV) using (A) primer pair $\mathrm{JQ} 3 \mathrm{D} 3 \mathrm{FF} / \mathrm{JQ} 3 \mathrm{D} 3 \mathrm{FR}$, and (B) primer pair JQ2C1FF/JQ2C1FR. Lane M, 1-kb DNA ladder; lanes 1 to 8, healthy apple, healthy cherry, apple with FAV (JCQ121-3), apple with FAV (JCQ121-4), cherry with CRLV (95CI193), cherry with CRLV (WSU-1), peach with CRLV (CP-1), cherry with CRLV (SC-DP), respectively; lane B is blank and lane N contains 50-bp DNA ladder. The solid arrow indicates the position of the 429-bp band and the open arrow indicates the position of the 370-bp band. 
Primer pairs JQ2C1FF/JQ2C1RR and JQ2D1FF/JQ2D1RR were not effective for the detection of FAV. Multiple or nonspecific bands were observed. In contrast, primer pairs JQ2C1FF/JQ2C1FR and JQ3D3FF/JQ3D3FR produced virus-specific fragments of 370 and $429 \mathrm{bp}$, respectively, with FAV (JCQ121-3 and JCQ1214) from $C$. quinoa and apple tissues (Table 2, Figs. 1 and 2). No reaction was observed with total RNA from healthy plants. In screening these primers with different isolates of CRLV in cherry and peach, the pair JQ3D3FF/JQ3D3FR reacted with all isolates of CRLV tested, whereas primers JQ2C2FF/JQ2C1FR only reacted with some cherry isolates and none of the peach isolates (Table 2, Fig. 2). FAV (JCQ121-3 and JCQ121-4, same isolate in different trees), and CRLV isolates 95CI193, WSU1, SC-DP, and CP-1 were detected using primers JQ3D3FF/JQ3D3FR (Fig. 2A). JCQ121-3, JCQ121-4, and CRLV isolates 95CI193 and WSU-1 were detected using primers JQ2C2FF/JQ2C2FR (Fig. 2B). CRLV isolates CP-1 and SC-DP were not detected by the latter primers. Both tests were conducted at the same time using the same total RNA preparations.

TC/RT-PCR. All sample grinding buffers were effective for the detection of FAV in $C$. quinoa, $0.01 \mathrm{M}$ potassium phosphate buffer containing $0.5 \%$ nicotine giving the strongest and most consistent bands (Fig. 3). This buffer was also the most consistent and reliable buffer for the detection of FAV in apple (leaf and budwood) and CRLV in cherry (leaf and budwood) (not shown). All studies were done two or more times.

Amino acid sequence alignment. The RT-PCR generated fragments (429 bp) using primer set JQ3D3FF/JQ3D3FR were compared using the BLAST programs (22). The deduced amino acid residues of the FAV (JCQ121-3)-associated fragment and the CRLV (1148-04) fragment were 95\% identical. Nonredundant protein database searches at NCBI using BLAST-X

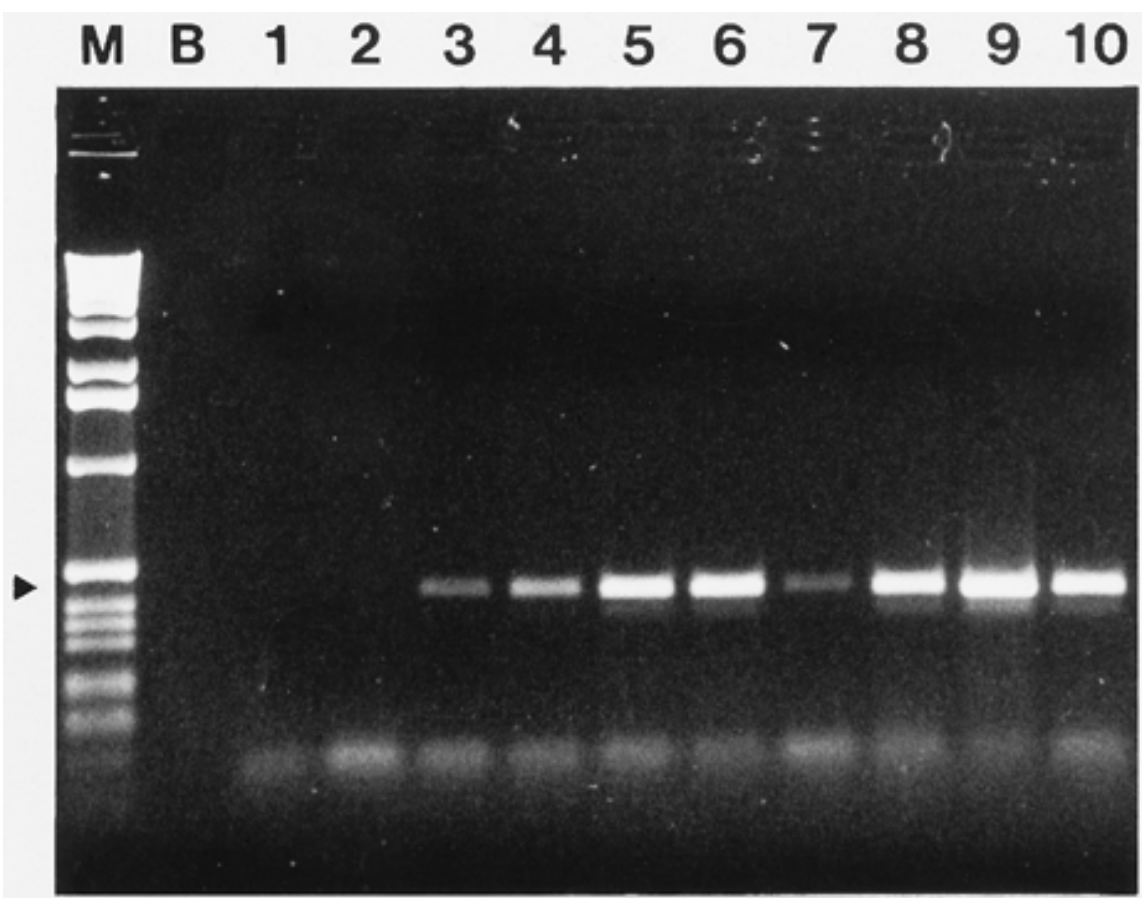

Fig. 3. Comparison of several sample grinding buffers used for the detection of Flat apple diseaseassociated-virus (FAV) in Chenopodium quinoa. Lane M, 1-kb DNA ladder; lane B, empty lane; lanes 1 and 2, healthy $C$. quinoa in buffer F; lanes 3 to 10, buffers A to H, respectively (7). The arrow indicates the position of the 429-bp band. revealed that the best matches were with Apple latent spherical virus (ALSV; 11). The derived protein sequences of the FAVand CRLV-associated amplified fragment were 64.2 and $63.5 \%$ identical, respectively, to a section in the $3^{\prime}$ region of the 108-kDa protein associated with RNA2 of ALSV (Fig. 4). The RT-PCR-generated fragment (370 bp) using the primer set JQ2C1FF/JQ2C1FR also produced the best match with RNA2 of ALSV (48\% identical) in the mid-region of the $108-\mathrm{kDa}$ protein. This indicated that both sets of primers target regions presumably on the RNA2 of FAV/CRLV genome.

Heat therapy analysis. Red Delicious apple infected with FAV (121-3) and heat treated to eliminate virus (treated plants identified as 125A-9) and untreated infected plants (isolate 121-3) included as controls were tested by RT-PCR and TC/RT-PCR using primers JQ3D3FF and JQ3D3FR. Tests were done at least twice on both first- and second-year growth with consistent results. All samples gave negative results, whereas the untreated infected controls tested positive as indicated by the presence of the FAV-specific 429-bp fragment (Fig 5). Known uninfected Red Delicious apple included as controls gave negative results. Fruit and leaves produced by trees subjected to heat therapy were normal in appearance.

\section{DISCUSSION}

Detection of flat apple disease has been limited to field indexing on the woody indicator Red Delicious apple (15). Field indexing on woody indicators is time consuming and often unreliable (21). The development of nucleic acid-based diagnostic tests such as dot blot hybridization and RTPCR improves our ability to perform more rapid virus assays to control and limit the spread of this economically important disease. Oligonucleotide primers, based on sequence information derived from cDNA clones generated using FAV-associated dsRNA, were used successfully in detecting both FAV and CRLV. Biological and serological evidence indicate that flat apple and cherry rasp leaf diseases are caused by related viruses (17-19). However, this is the first description of nucleic acid-based detection techniques and molecular evi-

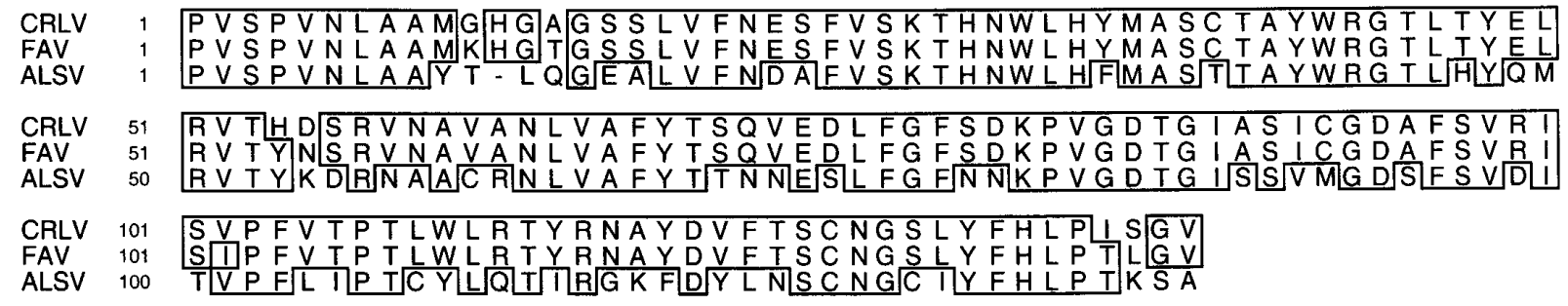

Fig. 4. Amino acid sequence alignment of the reverse transcription-polymerase chain reaction-amplified fragments (429 bp) of Flat apple disease-associated-virus (FAV, isolate JCQ121-3) and Cherry rasp leaf virus (CRLV, isolate 1148-04) obtained by searching the nonredundant database of the National Center for Biotechnology Information, using BLAST-X. Apple latent spherical virus (ALSV, accession number AB030941) provided the best matches. Residues are boxed if two or more amino acids are identical. 
dence confirming the relationship of FAV and CRLV. All isolates of FAV and CRLV were detected with the FAV-derived primer pair JQ3D3FF/JQ3D3FR, which produced a 429-bp fragment, suggesting that these primers target a conserved area of the virus genome. The primer pair JQ2C1FF/ JQ2C1FR, which amplifies a 370-bp fragment, recognized a region which was less conserved because only FAV and some isolates of CRLV were detected. Several other isolates of CRLV in cherry and all isolates of CRLV in peach were not detected using this primer pair. Therefore, choice for routine detection of FAV and CRLV by RT-PCR.

The viruses were also detected by TC/RT-PCR, with $0.01 \mathrm{M}$ potassium phosphate buffer containing $0.5 \%$ nicotine (final $\mathrm{pH}$ 9.6) being most effective for FAV in apple and CRLV in cherry. In a study of TC/RT-PCR detection of Apple stem grooving virus in apple, phosphate-buffered saline $(\mathrm{pH} 7.4)$ containing $2 \%$ polyvinylpyrrolidone (PVP) was identified as suggest that buffer efficiency depends more on the target virus than on the virus host. Availability of oligonucleotide primers allowed rapid and sensitive testing of plants treated by heat therapy to eliminate FAV. RT-PCR analysis is very sensitive (1) and allowed for greater confidence in the results obtained. The negative results primer pair JQ3D3FF/JQ3D3FR is a better the most effective buffer (7). These results

obtained by RT-PCR analysis of heattreated plants were consistent with the lack of any symptoms.

Database comparisons of the translated 429-bp product (JQ3D3 primers) and the 370-bp product (JQ2C1 primers) produced matches only with RNA2 of ALSV, a new member of the family Comoviridae (11). FAV- and CRLV-derived sequences displayed a high level of identity, confirming that both flat apple and rasp leaf diseases are caused by closely related viruses or isolates of the same virus. Primer pair JQ2C1FF/JQ2C1FR appears to target an area in the mid-region of RNA2 of the virus, whereas JQ3D3FF/JQ3D3FR targeted an area at the $3^{\prime}$ end of RNA-2. RNA2 produces a $108-\mathrm{kDa}$ polyprotein; the proteolytic products include three capsid proteins and a putative movement protein (11). Based on our RT-PCR and sequence analyses, it would appear that the $3^{\prime}$ end of this RNA species is more highly conserved. The 370-bp fragment associated with the mid region of RNA2 was less conserved, giving only $48 \%$ identity with the corresponding region of ALSV. This correlates well with the results of RT-PCR analysis and the limited effectiveness of the associated primers.

In Western blot analysis of FAV using CRLV-derived antiserum, two capsid protein subunits of approximately 22 and 24 $\mathrm{kDa}$ were identified. This profile is similar to CRLV as described by Stace-Smith and

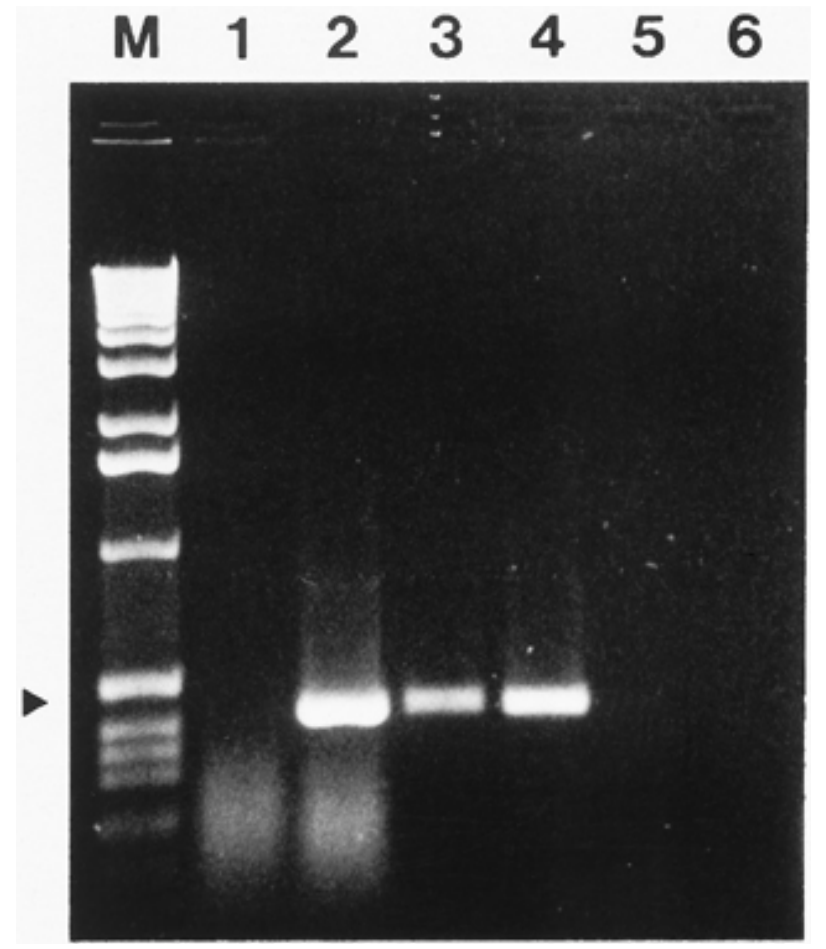

Fig. 5. Tube capture/reverse transcription-polymerase chain reaction evaluation of the efficacy of heat therapy for the elimination of Flat apple disease-associated-virus (FAV), isolate JCQ121-3. Lane M, 1-kb DNA ladder; lane 1, healthy Red Delicious apple; lane 2, Chenopodium quinoa with FAV (isolate JCQ121-3); lanes 3 and 4, first- and second-year growth, respectively, of untreated FAV (JCQ121-3)-infected Red Delicious apple; lanes 5 and 6, first- and second-year growth, respectively, from heat-treated Red Delicious apple originally infected with FAV JCQ121-3, subsequently identified as $125 \mathrm{~A}-9$. The arrow indicates the position of the 429-bp band.
Hansen (19), which is further evidence of virus relatedness. ALSV appears to be serologically unrelated to FAV/CRLV (11). ALSV has capsid protein subunits of 20 , 24 , and $25 \mathrm{kDa}$ (11), which indicate further differences; however, it is possible that gel concentrations used in the analysis of FAV and CRLV were unsuitable for resolving the 24- and $25-\mathrm{kDa}$ protein subunits. This should be elucidated by complete sequencing of the FAV/CRLV RNA2 species. In spite of the apparent differences, FAV/CRLV appear to be more closely related to ALSV than to other members of the family Comoviridae. Interestingly, CRLV is transmitted by the nematode $X$. americanum $(4,16)$, but no vector has as yet been associated with ALSV transmission (11).

Both FAV and CRLV were detected by RT-PCR in leaf and budwood tissues, fresh and after storage at $-80^{\circ} \mathrm{C}$. When compared to dot blot hybridization, RT-PCR was much more sensitive, which is consistent with studies of other viruses $(6,8)$. The detection of FAV and CRLV in budwood tissue should allow screening and certification of materials throughout the year, and the time taken to test the material was greatly reduced. Additional assays will be conducted on all available isolates to confirm this potential. This is an important benefit to both the pome fruit and stone fruit industry. Prior to these tests, FAV detection was limited to inoculation of trees and the long incubation required for the development of fruit symptoms. Further sequencing of FAV is in progress to determine the entire sequence of the virus genome, which will facilitate definitive classification of the virus and establish its relationship to ALSV and other members of the family Comoviridae.

\section{ACKNOWLEDGMENTS}

We thank D. Lye and M. MacLeod for technical assistance; S. Godkin for assistance with photography; C. Upton for assistance with sequence analysis; D. Stace-Smith for CRLV antiserum; G. Jesperson for samples of CRLV isolates KG-1 and SO-1-2; H. Larsen for isolates SC-DP, SC-RC, CP1, CP-A, and CP-S; and D. Thompson for isolates $1148-04$ and $1160-01$

\section{LITERATURE CITED}

1. Candresse, T., Macquaire, G., Lanneau, M., Bousalem, M., Wetzel, T., Quiot-Douine, L., Quiot, J. B., and Dunez, J. 1994. Detection of plum pox potyvirus and analysis of molecular variability using immunocapture-PCR. EPPO Bull. 24:585-594.

2. Devereux, J., Haeberli, P., and Smithies, O. 1984. A comprehensive set of sequence analysis programs for the VAX. Nucleic Acids Res. 12:387-395.

3. Griffin, H. G. 1994. Direct PCR screening of lambda and cosmid libraries. Pages 53-57 in: PCR Technology-Current Innovations. H. G. Griffin and A. M. Griffin, eds. CRC Press, Boca Raton, FL.

4. Hansen, A. J., Nyland, G., McElroy, F. D. and Stace-Smith, R. 1974. Origin, cause, host range and spread of cherry rasp leaf disease in North America. Phytopathology 64:721-727.

5. Hansen, A. J., and Parish, C. L. 1990. Trans- 
missible fruit disorders. Pages 77-78 In: Compendium of Apple and Pear Diseases. APS Press, St. Paul, MN.

6. Hu, J. S., Li, H. P., Barry, K., Wang, M., and Jordan, R. 1995. Comparison of dot blot, ELISA, and RT-PCR assays for the detection of two cucumber mosaic virus isolates infecting banana in Hawaii. Plant Dis. 79:902906.

7. James, D. 1999. A simple and reliable protocol for the detection of apple stem grooving virus by RT-PCR and in a multiplex PCR assay. J. Virol. Methods 83:1-9.

8. James, D., Jelkmann, W., and Upton, C. 1999. Specific detection of cherry mottle leaf virus using digoxigenin-labeled cDNA probes and RT-PCR. Plant Dis. 83:235-239.

9. James, D., and Upton, C. 1999. Single primer pair designs that facilitate simultaneous detection and differentiation of peach mosaic virus and cherry mottle leaf virus. J. Virol. Methods 83:103-111.

10. Laemmli, U. K. 1970. Cleavage of structural proteins during the assembly of the head of bacteriophage T4. Nature (London) 227:680685.

11. Li, C., Yoshikawa, N., Takahashi, T., Ito, T., Yoshida, K., and Koganezawa, H. 2000. Nu- cleotide sequence and genome organisation of apple latent spherical virus: a new virus classified into the family Comoviridae. J. Gen. Virol. 81:541-547.

12. MacKenzie, D. J., McLean, M. A., Mukerji, S., and Green, M. 1997. Improved RNA extraction from woody plants for the detection of viral pathogens by reverse transcriptionpolymerase chain reaction. Plant Dis. 81:222226.

13. Mink, G. I., Wample, R., and Howell, W. E. 1998. Heat treatment of perennial plants to eliminate phytoplasmas, viruses, and viroids while maintaining plant survival. Pages 332345 in: Plant Virus Disease Control. A. Hadidi, R. K. Khetarpal, and H. Koganezawa, eds. APS Press, St. Paul, MN.

14. Morris, T. J., and Dodds, J. A. 1979. Isolation and analysis of double-stranded RNA from virus infected plants and fungal tissue. Phytopathology 69:854-858.

15. Nemeth, M. 1986. Virus, Mycoplasma and Rickettsia Diseases of Fruit Trees. Akademiai Kiado, Budapest.

16. Nyland, G., Lownsbery, B. F., Lowe, S. K., and Mitchell, J. F. 1969. The transmission of cherry rasp leaf virus by Xiphinema americanum. Phytopathology 59:1111-1112.
17. Parish, C. L. 1976. A comparison between the causal agents of cherry rasp leaf and flat apple diseases. Acta Hortic. 67:199-202.

18. Parish, C. L. 1977. A relationship between flat apple disease and cherry rasp leaf disease Phytopathology 67:982-984.

19. Stace-Smith R., and Hansen, A. J. 1976 Cherry rasp leaf virus. No. 159, Descriptions of Plant Viruses. C.M.I./A.A.B., W. Culross and Sons, Ltd., Perthshire, Scotland.

20. Stace-Smith, R., and Hansen, A. J. 1976. Some properties of cherry rasp leaf virus. Acta Hortic. 67:193-198.

21. Stouffer, R. F., and Fridlund, P. R. 1989. Indexing using woody indicators. Pages 255 265 in: Virus and Viruslike Diseases of Pome Fruits and Simulating Noninfectious Disorders. P. R. Fridlund, ed. Wash. State Univ. Coop. Ext. Serv. Pullman.

22. Tatusova, T. A., and Madden, T. L. 1999. Blast 2 sequences - a new tool for comparing protein and nucleotide sequences. FEMS Microbiol Lett. 174:247-250.

23. Zimmerman, D., and Van Regenmortel, M. H V. 1989. Spurious cross-reactions between plant viruses and monoclonal antibodies can be overcome by saturating ELISA plates with milk proteins. Arch. Virol. 106:15-22.

On 17 February 2015, this article was changed. In Table 1, row 7, the sequence was corrected. 